\section{Postexposition administration of d-amphetamine impairs the habituation of rats to an open field}

\author{
JANDIRA MASUR* and REGINA MARIA WEY MÄRTZ* \\ Setor de Psicofarmacologia, Departamento de Bioquimica e Farmacologia \\ Escola Paulista de Medicina, São Paulo, Brasil
}

Control rats with a high index of defecation and injected with saline immediately after each exposure to an open-field arena showed a gradual decrease in defecation (habituation). However, when treated with d-amphetamine, rats with a high index of defecation even after 18 exposures eliminated a number of fecal boluses similar to that of the first exposure, indicating that the drug impaired habituation. These data support the hypothesis that amphetamine effects may possess aversive properties.

Posttrial administration of amphetamine, as other CNS stimulants, has been described as able to enhance the performance of animals in several tasks (Doty \& Doty, 1966; Krivanek \& McGaugh, 1968; McGaugh \& Dawson, 1971). However, a biphasic effect of amphetamine on rats trained in a Lashley III maze was recently reported (Breda et al, 1969); after an initial improvement there was a decay of performance. It was suggested that an aversive effect of the drug led to an approach-avoidance conflict (Breda et al, 1969). The present report presents the results of a study designed to detect the suggested aversive effect of amphetamine in an open-field arena. It is known that rats submitted for the first time to an open field show an increase of defecation (Hall, 1934; Candland \& Nagy, 1969), which declines (habituation) with repetition of the exposures (Broadhurst, 1957; Becker, 1969; Masur et al, 1971). We hypothesized that amphetamine, given immediately after exposure to the open field, could, through the suggested aversive effect, interfere with the habituation rate.

\section{SUBJECTS, DRUGS,}

AND PROCEDURE

Forty-nine 4-month-old female Wistar rats, weighing $200 \mathrm{~g}$ at the beginning of the experiment, were used. A standard food pellet diet and tap water were provided ad lib; handling was kept at a minimum. They were exposed for $3 \mathrm{~min}$ every $48 \mathrm{~h}$ to an open field identical to that described by Broadhurst (1960). The average number of fecal boluses in the three first exposures was used as the criterion to classify the rats into animals of high (average equal to or greater than 3 ) or low (average less than 3 ) index of defecation. Fifteen more exposures followed, every $48 \mathrm{~h}$,

* With a fellowship from Fundação de Amparo à Pesquisa do Estado de Sào Paulo (FAPESP). in which the rats received immediately after the exposure to the apparatus an IP injection of $2.0 \mathrm{mg} / \mathrm{kg}$ of d-amphetamine sulfate (Sigma Chemical Company) or of saline, or no injection. The number of animals in each group can be seen in Table 1 .

Table 1

Number and Index of Defecation of Rats Receiving Immediately After the Expositions to the Open Field $2.0 \mathrm{mg} / \mathrm{kg}$ of d-Amphetamine, Control Solution, or No Treatment

\begin{tabular}{lcc}
\hline & \multicolumn{2}{c}{ Defecation } \\
\cline { 2 - 3 } \multicolumn{1}{c}{ Treatment } & $\begin{array}{r}\text { High } \\
\text { Index } \\
(\mathrm{N})\end{array}$ & $\begin{array}{c}\text { Low } \\
\text { Index } \\
(\mathrm{N})\end{array}$ \\
\hline d-Amphetamine $(2 \mathrm{mg} / \mathrm{kg})$ & 7 & 10 \\
Control Solution $(1 \mathrm{ml} / \mathrm{kg})$ & 6 & 10 \\
No Treatment & 6 & 10 \\
\hline
\end{tabular}
the expositions ( $p \leqslant .05 ;$ Mann-Whitney test).
RESULTS AND DISCUSSION

Figure 1 shows the results obtained with amphetamine and saline in rats with a high index of defecation. As the rats that were not injected presented results similar to those of the saline group, they were omitted from the figure. It can be seen that control animals showed progressive habituation to the open field. Thus, at the 5 th session they already defecated significantly less when compared to their first exposure (Mann-Whitney test, $p \leqslant .05)$; with continuing exposures, defecation decreased to near zero. In opposition, the defecation of amphetamine-treated animals was similar from the 1st to the 12 th session. At the 13 th and 14 th exposures, there was a decrease, which, however, disappeared by increasing amphetamine dosage to $5.0 \mathrm{mg} / \mathrm{kg}$ (14th exposure). Because we felt that a larger number of animals should be used in order to draw a conclusion, a further experiment was conducted in which 30 male rats of high index of defecation were divided into three groups of 10 animals each, according to drug treatment mentioned above (amphetamine, control solution, no treatment). The results obtained were very similar to those already described.

This impairment of habituation cannot be explained on the basis of a direct action of amphetamine on the intestinal tract; thus, as the time interval between an injection and the next exposure to the apparatus was $48 \mathrm{~h}$, the animals when introduced to the open field were not under drug action. The drug had probably already

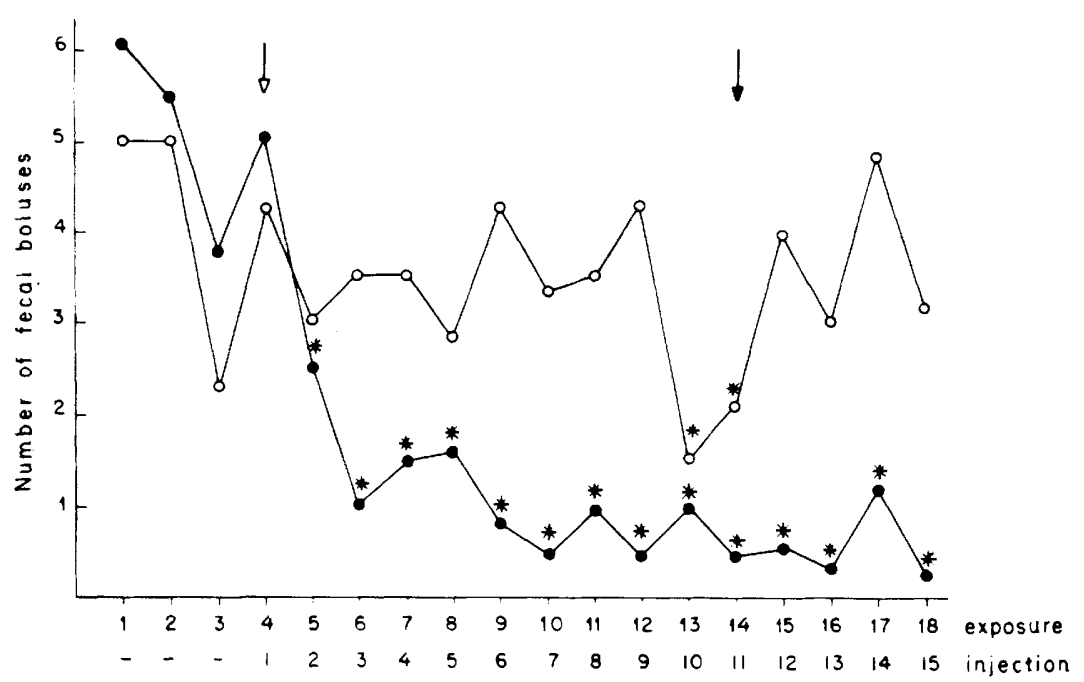

Fig. 1. Mean number of fecal boluses eliminated in the open field by rats of high index of defecation injected immediately after the expositions with d-amphetamine $(c)$ of control solution $(\bullet)$. White and dark arrows indicate the beginning of amphetamine administration of 2.0 and $5.0 \mathrm{mg} / \mathrm{kg}$, respectively. The asterisks indicate significant differences between thefirst and each one of 
been metabolized (Miller et al, 1971). On the other hand, defecation in an open field is considered an emotional fear-motivated response (Hall, 1934; Broadhurst, 1960; Denenberg, 1969) which decreases (habituation) as the situation becomes less fearful. Taking this into consideration, it is possible that our results indicate that amphetamine administered immediately after the exposure impaired the decrease of fear, possibly through an association between the open-field situation and the drug effects. Therefore, our data would support the suggested aversive effect of amphetamine (Breda et al, 1969). However, animals of low index did not respond to the amphetamine treatment; at the fourth exposure, the scores of elimination for amphetamine-treated and control rats with a low index of defecation were zero, a value which was maintained during the rest of the experiment. In this respect, Broadhurst (1964), Holland \& Gupta (1966), and Gupta \& Holland (1969) have also reported that rats of high and low index of defecation respond differently to drug treatments.

\section{REFERENCES}

BECKER, G. Initial and habituated autonomic reactivity in the male and female rat. Journal of Comparative \& Physiological Psychology, 1969, 69, 459-464.

BREDA, J. B., CARLINI, E. A., \& SADER, N.F.A. Effects of chronic administration of $(+)$-amphetamine on maze performance of the rat. British Journal of Pharmacology, 1969, 37, 79-86.

BROADHURST, P. L. Determinants of emotionality in the rat. I. Situational factors. British Journal of Psychology, $1957,48,1-12$.

BROADHURST, P. L. Experiments in psychogenetics. In H. J. Eysenck (Ed.), Experiments in personality. London: Routledge \& Kegan, 1960.

BROADHURST, P. L. The hereditary base for the action of drugs on animal behaviour. In: Animal behaviour and drug action. (Ciba Foundation Symposium) London: J. \& A. Churchill, 1964.

CANDLAND, D. K., \& NAGY, M. Z. The open-field: Some comparative data. Annals of the New York Academy of Sciences, 1969, 159, 831-851.

DENENBERG, V. H. Open-field behavior in the rat: What does it mean: Annals of the New York Academy of Sciences, 1969, $159,852-859$.

DOTY, B. A., \& DOTY, L. A. Facilitative effects of amphetamine on avoidance conditioning in relation to age and problem difficulty. Psy chopharmacologia (Berlin), 1966, 9, 234-241.

GUPTA, B. D. \& HOLLAND, H. C. An examination of the effects of stimulant and depressant drugs on escape/avoidance conditioning in strains of rats selectively bred for emotionality/non-emotionality. Psychopharmacologia (Berlin), 1969, 14 95-105.

HALL, C. S. Emotional behavior in the rat. I. Defecation and urination as measures of individual differences in emotionality. Journal of Comparative Psychology, $1934,18,385-403$.

HOLLAND, H. C., \& GUPTA, B. D. The effects of different doses of methylpentynol on escape/avoidance conditioning in two strains of rats selectively bred for high and low emotionality. Psychopharmacologia (Berlin), 1966, 9, 419-425.

KRIVANEK, J., \& McGAUGH, J, L. Effects of pentylenetetrazol on memory storage in mice. Psychopharmacologia (Berlin), $1968,12,303-321$.

MASUR, J, MÄRTZ, R. M. W., \& CARLINI, E. A. Effects of acute and chronic administration of Cannabis sativa and (-) $\Delta^{9}$-trans-tetrahydrocannabinol on the behavior of rats in an open-field arena. Psychopharmacologia (Berlin), 1971, 19 , 388-397.

McGAUGH, J., \& DAWSON, R. G. Modification of memory storage processes. Behavioral Science, 1971, 16. 45-63.

MILLER, K. W., BUSH, E. S., \& DINGELL $\mathrm{J}$ V. p-Chloroamphetamine-species differences in the rate of disappearance and the lowering of cerebral serotonin. Biochemical Pharmacology, 1971, 20, 500-503. 